\title{
Modelling the Enterprise Architecture Implementation in the Public Sector using HOT-Fit Framework
}

\author{
Hasimi Sallehudin ${ }^{1}$, Nurhizam Safie Mohd Satar ${ }^{2}$ \\ Faculty of Technology and Science Technology \\ Universiti Kebangsaan Malaysia, Selangor, Malaysia
}

\author{
Nur Azaliah Abu Bakar ${ }^{3}$, Rogis Baker ${ }^{4}$ \\ Razak Faculty of Technology and Informatics \\ Universiti Teknologi Malaysia, Kuala Lumpur, Malaysia ${ }^{3}$ \\ Faculty of Defence Studies and Management \\ National Defence University of Malaysia \\ Kuala Lumpur, Malaysia ${ }^{4}$
}

\author{
Farashazillah Yahya ${ }^{5}$ \\ Faculty of Computing and Informatics \\ Universiti Malaysia Sabah, Malaysia
}

\author{
Ahmad Firdause Md Fadzil ${ }^{6}$ \\ Faculty of Economy and Management Science \\ University of Sultan Zainal Abidin \\ Kuala Terengganu \\ Terengganu, Malaysia
}

\begin{abstract}
Enterprise architecture is very important to the public sector's IT systems that are developed, organized, scaled up, maintained and strategized. Despite an extensive literature, the research of enterprise architecture is still at the early stage in public the sector and the reason to explain the acceptance, as well as the understanding of the implementation level of EA services still remains unclear. Therefore, this study examines the implementation of EA by measuring the Malaysian public sector's influence factors of EA. Grounded by the HumanOrganization-Technology (HOT-Fit) Model, this study proposes a conceptual framework by decomposing Human characteristics, Organizational characteristics and Technological characteristics as main categories in assessing the identified factors. A total of 92 respondents in the Malaysian public sector participated in this study. Structural Equation Modelling with Partial Least Square is the main statistical technique used in this study. The study has revealed that human characteristics such as knowledge and innovativeness to EA and technological characteristics such as relative advantage and complexity of EA influence its implementation by the Malaysian public sector. Based on the findings, the theoretical and practical implications of the study as well as limitations and future works are also discussed.
\end{abstract}

Keywords-Enterprise architecture; public sector; HOT-Fit

\section{INTRODUCTION}

Enterprise architecture (EA) is a blueprint of the fundamental structures of an organization that describes the processes used for development of information technology (IT). The EA components and relations acts as an enabler for organization. EA aims to cover several issues and factors that determine organization to adopt EA. Many organizations have been implementing EA, but there are still many organizations have been unwilling to do so. This reluctance of organizations to implement EA contrasts with earlier forecasts by some of the proponents of EA that anticipated it to have been widely implemented by now. As far as EA implementation is concerned, literature and research into how organization continue with their strategy for enterprise architecture implementation is limited [1]. Moreover, study by [2] also pointed out that while extant research has studied EA, costs and benefits, potential applications, the influence factors of EA implementation in organization particularly in the public sector has not been empirically examined.

The phenomenon of EA implementation can be apprehended and measured by evaluating the organizational level of technology adoption. The phenomenon of technology adoption by organization can be defined as the adoption of an idea that is new to the organization adopting it. In this context, EA is conceptualized as a new idea of technology that related to the IT management to the organization to adopting and implementing it. Hence, many studies have developed models that explain or predict the adoption or implementation decision and extent of diffusion of technology within an organization. There are theories, models, theoretical frameworks and conceptual framework that have been developed to examine organizational technology adoption, characteristically dealing with decision to adopt, intention to adopt, intention to use, adoption, implementation and diffusion.

In addressing the aforesaid problems, this study explores and evaluates on critical success factors as well as evaluating the implementation of EA in the Malaysian public sector. Therefore, the contribution provided by the research presented in this paper is two-fold. First, we reveal and explain the influenced factors of EA implementation based on HumanOrganization-Technology (HOT-Fit) Model by [3]. Second, we develop a model that will be used to measure the significance of the identified factors influencing the EA implementation success within the Malaysian Public Sector context. 


\section{LITERATURE REVIEW}

\section{A. Enterprise Architecture in the Malaysian Public Sector}

In 2013, 1-Government Enterprise Architecture (1GovEA also known as MyGovEA starting in Jun 2018) has been announced by Malaysian Administrative Modernization and Management Unit (MAMPU). The purpose of MyGovEA is to strengthen and align ICT policy, standards and practices with the government vision and mission [4]. Moreover, the aim of MyGovEA is to assist the Malaysian public sector in aligning and unifying the business and IT strategy in order to meet the agency vision and mission towards better service delivery. The framework of MyGovEA as shown in Fig. 1, consist of three main components, namely, architecture domains, tools and repository, and methodology. Another supporting component is governance and principles.

MyGovEA architecture domains component is the core initiative for the Malaysian public sector EA. At the Business Architecture layer, capabilities and end-to-end business processes, functions, enterprise business outcomes, and their relationships to external entities required to execute business strategies is defined. For this component, the Malaysian public sector has initiated 1Malaysia Training Centre (1MTC also known as MyTC starting in Jun 2018) and 1Government Unified Communications (1GovUC also known as MyGovUC starting in Jun 2018). Meanwhile, for Information and Application Layers which deals with the structure and utility of information within the organization, and its alignment with its strategic as well as tactical and operational needs specifies the structure of individual systems based on defined technology. Thus, there are Public Sector Big Data Analytics (DSRA), Public Sector Data Dictionary (DDSA) and Public Key Infrastructure (PKI) initiatives that are initiated. Whereas, for technology layers, which defines the technology environment and infrastructure in which all IT systems operate, four initiatives were introduced which are Putrajaya Campus Network (PCN), 1Government Network (1Gov*Net also known as MyGov*Net starting in Jun 2018), Public Sector Data Centre (PDSA) and Malaysia Government Comprehensive Managed ICT Security Services (MyGSOC).

The four architecture domains largely represent the current state of practice in the discipline of MyGovEA. The successful of MyGovEA is not only captured by the four domains, but also the relationships between them. Having linkages between the four domains provides connection-of-sight to the relevant stakeholders of the EA.

\section{B. Critical Success Factors for Implementation of Enterprise Architecture}

A preliminary study was conducted to identify critical factors for successful implementation of EA. At this stage, a total of 239 papers that is matched with the keyword of "enterprise architecture" is selected from the various databases such as ScienceDirect, Wiley, JStor, EBSCO, Emerald, as well as InderScience. After screening process and filtering for selective criteria, only 16 papers selected for further metaanalysis process. The first paper used a meta-analysis of previous studies on critical success factors (CSF) for IT innovation adoption in government sector [5] as well as related to EA implementation in the government sector [6], [7] and [8]. Another paper used to identify CSFs was based on interview results where authors interviewed EA projects stakeholders that's include of an IT Manager and EA team members. After the meta-analysis process, the summary in the Table I reported critical success factors on the EA is classified based on HOT-fit themes:

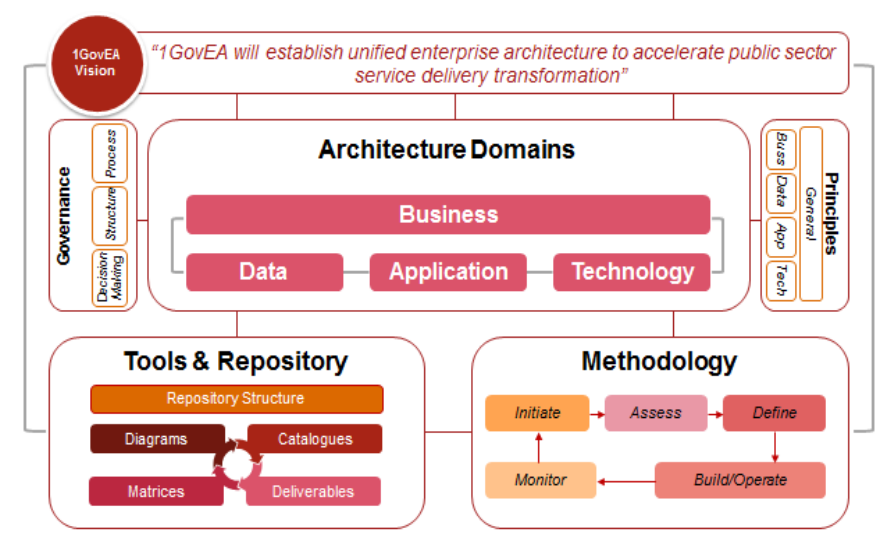

Fig. 1. MyGovEA for the Malaysian Public Sector (Source: www.mampu.gov.my).

TABLE I. CRITICAL SUCCESS FACTORS OF EA IMPLEMENTATION IN THE PUBLIC SECTOR BASED ON HOT-FIT FRAMEWORK

\begin{tabular}{|l|l|}
\hline Context & Factors \\
\hline \multirow{4}{*}{ Human } & EA team competency Knowledge \\
& and Skills \\
& Teamwork \\
& Silo thinking \\
& Innovativeness \\
\hline \multirow{5}{*}{ Organization } & Change Management \\
& Human Resource \\
& Top management support \\
& Organizational Readiness \\
& Financial \\
& Governance \\
& Project Championship \\
& Managerial Capability \\
& Formalization \\
\hline \multirow{2}{*}{ Technological } & Supporting tools \\
& Complexity \\
& Fragmented systems \\
& Legacy systems \\
& Privacy and securityCost \\
\hline
\end{tabular}

\section{THEORETICAL FOUNDATION}

The consideration of the IT systems implementation and adoption literature can be subdivided into two folds; individual and organizational level. In this paper the researchers conceptualized the EA implementation on the organizational level within the setting of the Malaysian public sector. Therefore, the HOT-fit model by [3] is utilized for the purpose of this study that fits concept between human, organizational and technological context. The following subsections describe the conceptualization of HOT-fit model as a foundation framework for EA implementation in the Malaysian public sector. 


\section{A. Human Factors}

Along with the IT innovation literature, many distinctive variables are possible determinants of organizational adoption of innovation. One of the distinctive contexts is the characteristics of human who are involved with IT innovation adoption. With a focus on the human factors in IT innovation adoption study, the HOT-fit model that integrates human dimensions by [3] is suitable as a based framework to evaluate human context for EA implementation in the Malaysian Public sector.

Previously, [9] define IT adoption is determined by the characteristics of the individuals in the organization. Later, [10] in his study has included Chief Executive Officer (CEO) characteristics to his theoretical framework on IS adoption. He found that the characteristic of CEO is a distinct domain for SME to adopt IS.

Furthermore, [11] and [12] argued that IT professional participation to the IT activities in the organization requires skills and knowledge in technology, interpersonal as well as management to effectively integrate IT with business in the organization. Additionally, they also proposed that IT professionals must able to learn past, current and future IT development in organization to meet the evolving needs. Most IT professionals just hold their skills and knowledge on the previous IT technology without the motivation or innovativeness to explore and learn current trends of the IT. As a reality, IT professionals likewise needs to upgrade their knowledge and change their innovativeness with the changing of IT development, business needs and the scope of IT requirement in the organization. For that IT officer innovativeness and IT officer knowledge will be examined in this study to evaluate the affect to EA implementation by the Malaysian public sector.

1) IT officer innovativeness: As a norm in the Malaysian public sector that IT officer in the organization is considered as the owner, influencer or decision maker for organization to implement IT innovation. The involvement of IT officer in the organizations' IT project start with the proposal phase until the implementation phase. In the same systems such as an organization, other members relative to other member innovativeness to accept and adopt new ideas [13]. This idea is employed by [14] to apprehend CIO innovativeness in the direction of the adoption of recent information technology. Moreover, an innovativeness of IT officer is prepared to take the risks and typically choose new answers which have now not been tried previously. Latest literatures found that the significant IT officer innovativeness positively influence the adoption of IT innovations. Therefore, the following hypotheses were formulated:

H1: IT officer innovativeness will have positive effect to EA implementation in the Malaysian public sector.

2) IT officer knowledge: The knowledge in the context of this study states the technical knowledge about technologies by IT officer. The technical knowledge states the ability to perform all of the IT task required in the IT project such as technical capability, processes, tools and skills. The lack of technical knowledge, expertise and skills in by the IT officer contribute to the slow rate of IT innovation adoption. During the initiation phase, the organization gathers the necessary information about IT innovation for new IT project and the evaluation of the information deeply depends on the knowledge of IT officer. Thus, the capability of organization for implementing the new IT project such as EA, the necessary skilled and adequate technical knowledge of IT officer for adoption is required. This argument supported by the previous study on the adoption or human resource information systems (HRIS) in Singapore by [15] which found that the success and sustainable growth of HRIS because of the availability of technical knowledge by IT professional. Next, in the context of cloud computing implementation, [11] and [14] argued that IT officer must have a knowledge about the types of cloud computing such as deployment models and also able to choose the right models for organizations. Therefore, in the context of EA implementation, IT officer must have a knowledge about the concept, tools, as well as the process of EA implementation. Thus, the following hypothesis were formulated.

H2: IT officer knowledge will have positive effect to EA implementation in the Malaysian public sector.

\section{B. Organizational Factor}

The context of organizational factor in this study represents the organizational characteristic that is described as the organizational characteristics in the Malaysian public sector. For instance, the organizational characteristics that will determine the capability of the Malaysian public sector to implement and practice EA such as current IT readiness and the support of top management.

1) Organizations' IT readiness: IT readiness is conceptually defined by the three dimensions. It makes more sense to state that an organization has higher level of IT readiness because it possesses IT human resource, IT infrastructure and system integration than it does to state that the higher-level IT readiness leads to higher level IT human resource, IT infrastructure, and system integration [17]. The three dimensions form the overall IT readiness as a composite. IT human resource, infrastructure, and system integration reflects IT readiness from three different aspects respectively. The lack of one aspect may lead to incomplete evaluation of the overall IT readiness in a firm. These subdimensions of IT readiness are essentially distinct and independent from each other especially for EA implementation that consist of all these elements of IT readiness. For example, a comprehensive IT documentation policy and guidelines as well as IT infrastructure can provide standards for other IT components such as IT architecture (software, hardware, data exchange, communications, operating systems, etc.) and ensure the smooth transition of "as-is" to "to-be", which are required to implement EA. Thus, the following hypothesis were formulated. 
H3: Organizational IT readiness has a significant relationship with the implementation of EA.

2) Top management support: In the big organization such as the public sector, the ultimate influencer for the new IT project or IT innovation implementation is the support from the top management [16], [18] and [19]. In this study, top management support refers to the extent to which top managements are involved in and promote the implementation of EA by the organization. Director or Head of Department are the individuals who are authorized and responsible to make a decision concerning strategic movements and resource allocation, which can also substantively impact implementation process and results of IT innovation within the organization. Top management can create a climate that favors EA implementation by motivating and thinking about process innovation with EA, overcoming organizational inertia or structural barriers, ensuring and continuing attention to EA initiatives and facilitating strategic renewal to align EA with business objectives. Therefore, the support from the top management is important for the new IT project like EA to be implemented. Subsequently, top management support creates supportive environment and impart an appropriate resource such as financial as well as human resource. Hence, the following hypothesis were formulated.

H4: Top management support has a significant relationship with the implementation of EA.

\section{Technological Factor}

The context of technological factors in this study represents the characteristics of EA tools that might determine the likelihood of EA implementation by the Malaysian public sector. This assertion is supported by the previous studies which is conceptualize the characteristics of technology such as cloud computing, e-business, mobile application, human resource systems, social media applications, enterprise resource planning, customer relationship management as well as enterprise architecture as an important factor for the implementation and adoption of such technologies [20], [21]. Moreover, the literature additionally recommended further research on the influences of the technological characteristics such as relative advantage and complexity for EA implementation in the public sector [4], [12].

1) Relative advantage: Relative advantage refers to the benefits of the technology can provide to the organization. The degree of the benefits evaluated in terms of productivity, profitability, time and effort, and cost. Recent study by [2] indicates that an organization will get a lot of benefits by implementing EA such as effective IT decision support, ensuring data integrity and security, facilitating data analytics as well as easing the setting and enforcing standards for "tobe" IT environment. In the context of the Malaysian public sector, the benefits of EA implementation (MyGovEA for instance) will create better opportunities for the agency to enhance their IT capabilities in their organization. This advantage expected that EA's positively related to implementation of EA in the Malaysian public sector. Thus, the next hypothesis was formulated.

H5: Relative advantage has a significant relationship with the implementation of EA.

2) Complexity: Complexity of the innovation defined as the degree of difficulty to understand and use of that innovation [13]. In the context of EA, the complexity of tools such as ArchiMate and Microsoft Visio as well as other modelling developing tools. Moreover, the complexity of the EA management and process also an inhibitor to implementation of EA. These complexities create greater uncertainty for successful implementation of EA in the Malaysian public sector and increase the risk of the implementation process. Thus, the following hypothesis were formulated.

H6: Complexity has a significant relationship with the implementation of EA.

\section{RESEARCH DESIGN}

\section{A. Research Samples}

The sampling frame of this study was 730 various departments in the Malaysian public sector. Manager or Head of IT Department and senior IT officer from each department was selected as a respondent. The selection of the respondents based on the roles as IT officer because they are fully involved in the IT project as an owner, leader or members in their department.

\section{B. Measures Operationalization}

The dependent variable in this study is the implementation of EA in the Malaysian public sector and the independent variables are within the context human, organization, technology discussed above. All measurement items adopted from established and various existing literatures. The 5-point Likert scale ranging from 1 to 5 (strongly disagree to strongly agree) used to measure the statements in the questionnaire.

\section{Data Analysis}

Data analysis process involved in this study is descriptive analysis, measurement and structural model analysis. Statistical analysis package, SPSS and Structural Equation Modelling (SEM) Partial Least Square (PLS) used as a software for the data analysis process. The data screening process such as missing data, straight lining, normality test, as well as nonresponse bias was conducted before further data analysis process. Out of 200 questionnaires distributed, only 92 respondents selected for further analysis.

Next, descriptive analysis using SPSS 21.0 was conducted to get the demographic background of respondents followed with the measurement analysis of the questionnaires using SmartPLS 3.0. All measurements were analysed to measure the reliability and validity of the items of the questionnaire and variables. Finally, structural analysis was conducted to test the hypotheses and validate the research model. 


\section{REsults}

\section{A. Demographic Backgrounds}

The background of the respondents in this research is illustrated in Table II. General background of the respondents such as age, gender, education, working experience and job position were derived from the first part of questionnaire. The information from Table II shows that the majority of the respondents are mainly a senior of IT officer in the various departments in the Malaysian public sector. They also have working experience more than 5 years. Therefore, their response to the questionnaire in this study is meaningful and reliable to represent their department.

\section{B. Measurement Model Analysis}

For the measurement model analysis, measuring the reliability and validity of the item's questionnaires was conducted using SmartPLS. An average variance extracted (AVE) used to measure the reliability of the item questionnaires and represent as factor loading. The criteria or cut-off value for the items to be considered as reliable is 0.7 and above [22]. Next, Cronbach's Alpha $(\alpha)$ and composite reliability (CR) used as a measurement criterion to assess the reliability and internal consistence reliability of the variables. The required value to meet the criteria for reliability is 0.5 for Cronbach's Alpha and 0.7 for CR [22].

TABLE II. DESCRIPTIVE STATISTICS OF DEMOGRAPHIC BACKGROUNDS

\begin{tabular}{|c|c|c|c|}
\hline Background & Information & Frequency & Percentage $\%$ \\
\hline \multirow{2}{*}{ Gender } & Male & 51 & 55.4 \\
\hline & Female & 41 & 44.6 \\
\hline \multirow{5}{*}{ Age } & 25 or less & 12 & 13.0 \\
\hline & $26-35$ & 13 & 14.1 \\
\hline & $36-45$ & 30 & 32.6 \\
\hline & $46-55$ & 22 & 23.9 \\
\hline & $56-60$ & 15 & 16.3 \\
\hline \multirow{5}{*}{$\begin{array}{l}\text { Education } \\
\text { Level }\end{array}$} & $\mathrm{PhD}$ & 2 & 2.2 \\
\hline & Master Degree & 11 & 12.0 \\
\hline & Bachelor Degree & 53 & 57.6 \\
\hline & Diploma & 12 & 13.0 \\
\hline & Others & 14 & 15.2 \\
\hline \multirow{5}{*}{$\begin{array}{l}\text { Present } \\
\text { Position }\end{array}$} & $\begin{array}{l}\text { Chief Information } \\
\text { Officer (CIO) }\end{array}$ & 3 & 3.3 \\
\hline & $\begin{array}{l}\text { Manager/Head of IT } \\
\text { Agency }\end{array}$ & 8 & 8.7 \\
\hline & IT Officer & 68 & 73.9 \\
\hline & IT Staff & 11 & 12.0 \\
\hline & Others & 2 & 2.2 \\
\hline \multirow{5}{*}{$\begin{array}{l}\text { Working } \\
\text { Experience in } \\
\text { the Malaysian } \\
\text { Public Sector }\end{array}$} & Less than 2 years & 8 & 8.7 \\
\hline & Between 2-4 years & 12 & 13.0 \\
\hline & Between 5-7 years & 19 & 20.7 \\
\hline & Between $8-10$ years & 25 & 27.2 \\
\hline & More than 10 years & 28 & 30.4 \\
\hline \multirow{5}{*}{ Agency Types } & Federal & 38 & 41.3 \\
\hline & Federal Statutory & 15 & 16.3 \\
\hline & State & 10 & 10.9 \\
\hline & State Statutory & 16 & 17.4 \\
\hline & Local Authority & 13 & 14.1 \\
\hline
\end{tabular}

From Table III, the factor loading of the items above the value 0.5 which is ranging between 0.934 and 0.703 and satisfied the criteria for reliability test stated by Hair et al. 2010. The value of the AVE, $\alpha$ and CR also meet the criteria of the reliability test and higher than cut-off values for each criterion, thus the measurement of the items in this study is reliable.

Next, this study proceeded to test of the construct validity. The analysis used to validate the data and variables in this study is discriminant validity. In this test, the evaluation is done by comparing between correlation value and square root of AVE for each variable. The result in the Table IV shows that the value for inter-correlation is lower than the value of square roots of AVEs. Thus, the validity for measurement instruments in this study is validated. Fig. 2 illustrates the measurement model of this study.

\section{Structural Model Analysis}

The next analysis performed for this study was the evaluation of the hypotheses. In this analysis, all hypotheses in this study represent by the arrow relationship from independent variables to the dependent variable in the SmartPLS model. In this study, the method first order and second order construct was applied as suggested by [23]. There are two level of independent variables conceptualized as a second order and first order construct. For the first order, all 6 independent variables form a first order construct. For the second order construct, human, organizational and technological form as combination for their first order variables. For instance, second order construct of human is representing by combining all items from knowledge and innovativeness. Similar to organizational and technological construct which formed by the combination of their first order constructs.

TABLE III. QUALITY OF THE MEASUREMENT MODEL

\begin{tabular}{|c|c|c|c|c|c|}
\hline Latent Variable & Items & Loading & AVE & $\mathrm{CR}$ & CA \\
\hline \multirow{3}{*}{ Knowledge } & KNW1 & 0.8265 & 0.7038 & 0.8769 & 0.7893 \\
\hline & KNW2 & 0.8667 & & & \\
\hline & KNW3 & 0.8229 & & & \\
\hline \multirow{3}{*}{ Innovativeness } & INNOV1 & 0.9276 & 0.8155 & 0.9298 & 0.886 \\
\hline & INNOV2 & 0.9340 & & & \\
\hline & INNOV3 & 0.8448 & & & \\
\hline \multirow{3}{*}{$\begin{array}{l}\text { Top Management } \\
\text { Support }\end{array}$} & TMS1 & 0.7720 & 0.6605 & 0.8529 & 0.7386 \\
\hline & TMS2 & 0.9016 & & & \\
\hline & TMS3 & 0.7567 & & & \\
\hline \multirow{3}{*}{$\begin{array}{l}\text { Organizational } \\
\text { Readiness }\end{array}$} & ORS1 & 0.8885 & 0.8081 & 0.9266 & 0.8805 \\
\hline & ORS2 & 0.9394 & & & \\
\hline & ORS3 & 0.8673 & & & \\
\hline \multirow{3}{*}{ Relative advantage } & RA1 & 0.8247 & 0.7078 & 0.879 & 0.7939 \\
\hline & RA2 & 0.8312 & & & \\
\hline & RA3 & 0.8674 & & & \\
\hline \multirow{3}{*}{ Complexity } & CPLX1 & 0.8128 & 0.6973 & 0.8733 & 0.7813 \\
\hline & CPLX2 & 0.8891 & & & \\
\hline & CPLX3 & 0.8004 & & & \\
\hline \multirow{4}{*}{$\begin{array}{l}\text { EA } \\
\text { Implementation }\end{array}$} & IMPL1 & 0.8009 & 0.5712 & 0.8417 & 0.7634 \\
\hline & IMPL2 & 0.7030 & & & \\
\hline & IMPL3 & 0.7586 & & & \\
\hline & IMPL4 & 0.7574 & & & \\
\hline
\end{tabular}


Next, model analysis was performed to examine the significant of the relationship between independent variables and dependent variable. This test also known as hypotheses or the value of the t-value. Bootstrapping process was initiated to generate the t-value of the model analysis. The total number of 5000 samples and two-tailed criteria used $(t>1.67)$ in this study as suggested by [24].

TABLE IV. DISCRIMINANT VALIDITY OF LATENT VARIABLES

\begin{tabular}{|c|c|c|c|c|c|c|c|c|}
\hline & & 1 & 2 & 3 & 4 & 5 & 6 & 7 \\
\hline 1 & Knowledge & 0.8389 & & & & & & \\
\hline 2 & Innovativeness & 0.6624 & 0.9031 & & & & & \\
\hline 3 & Top Management Support & 0.2085 & 0.2105 & 0.8127 & & & & \\
\hline 4 & Organizational Readiness & 0.3294 & 0.3631 & 0.5469 & 0.8989 & & & \\
\hline 5 & Relative advantage & -0.017 & 0.1011 & 0.3320 & 0.3317 & 0.8413 & & \\
\hline 6 & Complexity & 0.4254 & 0.4169 & 0.2268 & 0.2250 & 0.1314 & $\mathbf{0 . 8 3 5 0}$ & \\
\hline 7 & EA Implementation & 0.0861 & 0.3362 & 0.1808 & 0.0861 & 0.3784 & 0.322 & 0.7558 \\
\hline
\end{tabular}

TABLE V. RESULTS OF HYPOTHESIS TESTING

\begin{tabular}{|l|l|l|l|l|l|}
\hline & Hypotheses & Path Coefficient & $T$ value & $P$ value & Decision \\
\hline H1 & INNOV -> EA IMPL & 0.1777 & 2.392 & 0.02 & SUPPORTED \\
\hline H2 & KNOW -> EA IMPL & 0.1515 & 2.292 & 0.02 & SUPPORTED \\
\hline H3 & ORS READINESS -> EA IMPL & -0.0931 & 1.014 & 0.31 & NOT SUPPORTED \\
\hline H4 & TMS -> EA IMPL & -0.0719 & 1.048 & 0.30 & NOT SUPPORTED \\
\hline H5 & RA -> EA IMPL & 0.3070 & 2.331 & 0.02 & SUPPORTED \\
\hline H6 & COMPLEXITY -> EA IMPL & 0.2703 & 2.723 & 0.01 & SUPPORTED \\
\hline
\end{tabular}

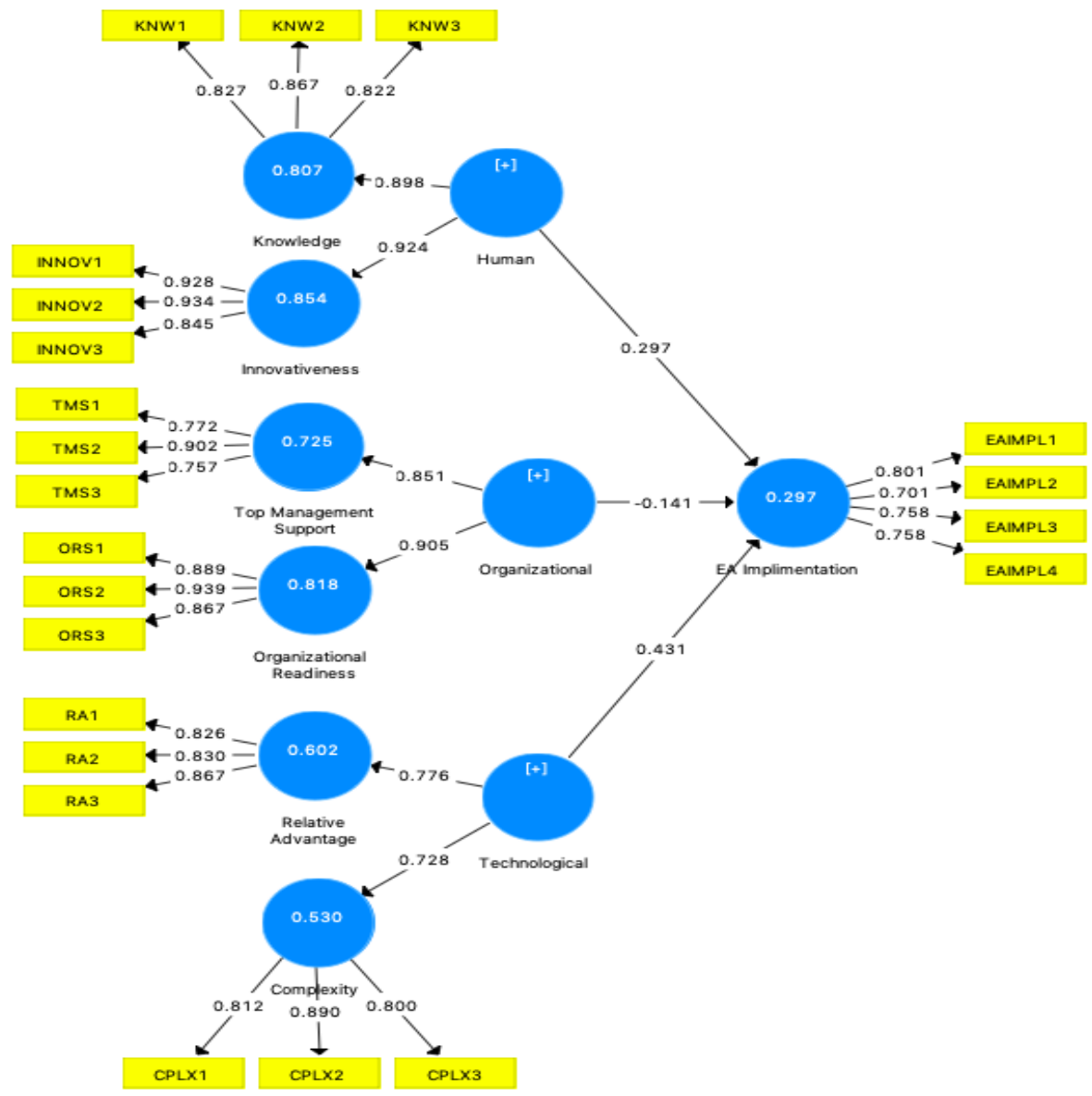

Fig. 2. Measurement Model. 
The result of the structural model analysis in this study is shown in Table $\mathrm{V}$. The result shows that the $\mathrm{t}$-value of relationship between knowledge, innovativeness, relative advantage and complexity is greater than 1.67 , thus $\mathrm{H} 1, \mathrm{H} 2$, H5 and H6 significantly affect to EA implementation in the Malaysian public sector. The results also revealed that both total effects for organizational readiness and top management support not significant to EA implementation by the Malaysian public sector, thus both hypotheses $\mathrm{H} 3$ and $\mathrm{H} 4$ is rejected.

The last step of structural model analysis is the evaluation percentage variance or $\mathrm{R}^{2}$ value of dependent variable. The value of $R^{2}$ represents the percentage of variation explained by the independent variables to predict the accuracy of the model. The higher value of $\mathrm{R}^{2}$, the higher predictive accuracy of the independent variables toward dependent variable. According to [25], the model having $\mathrm{R}^{2}$ as 0.67 and above considered substantially accurate. While the model that having the value of $\mathrm{R}^{2}$ below than 0.19 are considered as weak accuracy. The accuracy of moderate if the value of $\mathrm{R}^{2}$ is between 0.19 and 0.67. In this study, the result of $R^{2}$ value for $E A$ implementation is 0.30 , thus can be consider moderate accuracy predicted by human, organizational and technological variables.

\section{DISCUSSION}

The objective of this study is to identify and evaluate the factors that influence the implementation of EA by the Malaysian public sector. After conducting the process of preliminary research, HOT-fit model was selected as a foundation theory to develop the model for this research to determine the factors in the context of human, organizational and technological. Along with the research process and analysis conducted, the results show that both human and technological factors positively influence the implementation of EA by the Malaysian public sector. These results in line with the previous research in their study in other IT innovation adoption and implementation [26], [27] and [28]. These results suggest that, the factors of IT officer knowledge and innovativeness toward EA positively influence the department in the Malaysian public sector to implement EA.

Next, the results of this study also show that technological factors such as relative advantage and complexity influence the implementation of EA by the Malaysian public sector. The results of this study confirm the findings by the previous study within the context of other IT innovation adoption and implementation [29]. The benefits of EA implementation were informed by the IT officer as well as the complexity of process and EA tools. This factor also inter-correlated with the knowledge of EA by the IT officer. From the knowledge gain, IT officer proves that EA is beneficial to be implemented by their department.

However, the results of this study found that organizational factor had been insignificant to the EA implementation by the Malaysian public sector. The role of the organization in influencing the team on the EA implementation seems to be insignificant. The support of the top management and IT readiness by the department seems to be not the factors to the EA implementation. This can be argued that, the structure of administrative level of the department in the Malaysian public sector might factors. The respondents might be confused with the support of the top management in this study either their decision maker within the department or the decision maker among the ministry level. Departments in the public sector also serve with different level of decision maker. Some department receives direction from the ministry level and some of the departments receive the direction from their Head of Department. In terms of IT readiness, in can be argued that the implementation of EA does not require the support of IT infrastructure and resources. The process of EA implementation is involved with management process and little features on EA tools. Thus, the requirement of complete IT infrastructure and human resource seems to be not required.

\section{CONCLUSIONS}

This paper proposes to develop an extended EA implementation model for the Malaysian public sector that is composed of HOT-fit such as human, organizational and technological factors as independent variables and EA implementation as dependent variable. All four independent variables, IT officer knowledge and innovativeness on EA as well as relative advantage and complexity of EA significantly influence the EA implementation. However, two independent variables, top management support and IT organizational readiness not influence the EA implementation. Thus, the results of this study contribute to the body of knowledge in the context of HOT-fit model and EA.

After conducting the analysis based on quantitative method, this study provides a view for the important factors that might play crucial roles in the EA implementation process in the Malaysian public sector. However, this study needs to be further validated using qualitative method either by the case study or details interview with the main player of EA in the Malaysian public sector.

\section{ACKNOWLEDGEMENTS}

We gratefully acknowledge that this research paper was funded by the National University of Malaysia Research Grant GGPM-2018-012. We would also like to acknowledge the editors and anonymous reviewers for their valuable guidance.

\section{REFERENCES}

[1] F. Nikpay, R. Ahmad, B. D. Rouhani, and S. Shamshirband, "A systematic review on post-implementation evaluation models of enterprise architecture artefacts," Inf. Syst. Front., pp. 1-20, 2016.

[2] N. A. A. Bakar, N. Kama, and S. Harihodin, "Enterprise architecture development and implementation in public sector: The Malaysian perspective," J. Theor. Appl. Inf. Technol., vol. 88, no. 1, pp. 176-188, 2016.

[3] M. M. Yusof, J. Kuljis, A. Papazafeiropoulou, and L. K. Stergioulas, “An evaluation framework for Health Information Systems: human, organization and technology-fit factors (HOT-fit)," Int. J. Med. Inform., vol. 77, no. 6, pp. 386-398, 2008.

[4] N. A. A. Bakar, S. Harihodin, and N. Kama, "Assessment of Enterprise Architecture Implementation Capability and Priority in Public Sector Agency," Procedia Comput. Sci., vol. 100, pp. 198-206, 2016.

[5] M. M. Kamal, "IT innovation adoption in the government sector: Identifying the critical success factors," J. Enterp. Inf. Manag., 2006.

[6] M. M. Kamal and M. Themistocleous, "Investigating EAI adoption in the local government authorities: A case of mapping the influential factors on the adoption lifecycle phases," Transform. Gov. People, Process Policy, vol. 3, no. 2, pp. 190-212, 2009. 
[7] Y. Abd.Rahim, M. Mohamad, N. Safie, and Z. And Rahim@ Ab Rasim, "Faktor Kejayaan Kritikal, Cabaran Serta Kebaikan Pelaksanaan Seni Bina Perusahaan ( EA ) Dalam Agensi Awam Malaysia," MALTESAS Multi-Disciplinary Res. J., vol. 3, no. 2, pp. 62-71, 2018.

[8] N. A. A. Bakar, M. N. Kama, and H. Selamat, "Service-Oriented Enterprise Architecture ( SoEA ) Adoption and Maturity Measurement Model: A Systematic Literature Review," Int. J. Comput. Electr. Autom. Control Inf. Eng., vol. 7, no. 12, pp. 334-345, 2013.

[9] J. Y. Thong and C. S. Yap, "CEO characteristics, organizational characteristics and information technology adoption in small businesses," Omega, vol. 23, no. 4, pp. 429-442, Aug. 1995.

[10] J. Y. Thong, "An integrated model of information systems adoption in small businesses," J. Manag. Inf. Syst., vol. 15, no. 4, p. 187, 1999.

[11] H. Sallehudin, R. C. Razak, and M. Ismail, "Factors Influencing Cloud Computing Adoption in the Public Sector: An Empirical Analysis," J. Entrep. Bus., vol. 3, no. 1, pp. 30-45, 2015.

[12] H. Sallehudin, R. C. Razak, M. Ismail, A. F. M. Fadzil, and R. Baker, "Cloud Computing Implementation in the Public Sector: Factors and Impact," Asia-Pacific J. Inf. Technol. Multimed., vol. 7, no. 2-2, pp. $27-$ 42, 2019.

[13] E. M. Rogers, Diffusion of innovations. 5th edition, New York: Free Press., 2003.

[14] R. Agarwal and J. Prasad, "A Conceptual and Operational Definition of Personal Innovativeness in the Domain of Information Technology," Inf. Syst. Res., vol. 9, no. 2, pp. 204-215, Jun. 1998.

[15] T. S. H. Teo, G. S. Lim, and S. A. Fedric, "The adoption and diffusion of human resources information systems in Singapore," Asia Pacific J. Hum. Resour., vol. 45, no. 1, pp. 44-62, Apr. 2007.

[16] H. Sallehudin, R. C. Razak, and M. Ismail, "Determinants and Impact of Cloud Computing Implementation in the Public Sector," J. Adv. Inf. Technol., vol. 7, no. May, pp. 245-251, 2016.

[17] C. Y. Lin and Y. H. Ho, "Determinants of Green Practice Adoption for Logistics Companies in China," J. Bus. Ethics, vol. 98, no. 1, pp. 67-83, Jun. 2010.

[18] J. Y. Xin, T. Ramayah, P. Soto-Acosta, S. Popa, and T. Ai Ping, "Analyzing the Use of Web 2.0 for Brand Awareness and Competitive Advantage: An Empirical Study in the Malaysian Hospitability Industry," Inf. Syst. Manag., vol. 31, no. 2, pp. 96-103, Apr. 2014.
[19] S. M. Motahar, M. Mukhtar, N. S. Mohd Satar, M. Y. Maarif, and S. Mostafavi, "Revisiting the Diversification on the Implementation of Open Source ERP Teaching Models," Jour Adv Res. Dyn. Control Syst., vol. 10, no. 09, pp. 2379-2385, 2018.

[20] A. Mukred, D. Singh, and N. Safie, "Investigating the impact of information culture on the adoption of information system in public health sector of developing countries,” Int. J. Bus. Inf. Syst., vol. 24, no. 3, p. 261, 2017.

[21] Y. A. Rahim, M. Mohamad, N. Safie, A. Rahim, and A. Rasim, "Critical Success Factors, Challenges and Benefits of Enterprise Architecture (EA) in the Malaysian Public Agency," MALTESAS Multi-Disciplinary Res. J., vol. 3, no. 2, pp. 62-71, 2018.

[22] J. F. Hair, W. C. Black, B. J. Babin, and R. E. Anderson, Multivariate Data Analysis (6th ed.). 2006.

[23] P. B. Lowry and J. Gaskin, "Partial least squares (PLS) structural equation modeling (SEM) for building and testing behavioral causal theory: When to choose it and how to use it," IEEE Trans. Prof. Commun., vol. 57, no. 2, pp. 123-146, 2014.

[24] J. F. . Hair, G. T. M. Hult, C. M. Ringle, and M. Sarstedt, A Primer on Partial Least Squares Structural Equation Modeling (PLS-SEM). Thousand Oaks, CA: Sage Publications, Inc., 2014.

[25] W. W. Chin, "Issues and opinion on structural equation modeling," MIS Q., vol. 22, no. 1, pp. vii-xvi, 1998.

[26] L. Ahmadian, S. Salehi Nejad, and R. Khajouei, "Evaluation methods used on health information systems (HISs) in Iran and the effects of HISs on Iranian healthcare: A systematic review," Int. J. Med. Inform., vol. 84, no. 6, pp. 444-453, 2015.

[27] A. Meri et al., "Modelling the utilization of cloud health information systems in the Iraqi public healthcare sector," Telemat. Informatics, vol. 36, no. April 2018, pp. 132-146, 2019.

[28] M. Mohammadi and M. Mukhtar, "A service-oriented methodology for supporting business process architecture layers in supply chain management," Int. J. Inf. Syst. Supply Chain Manag., vol. 10, no. 4, pp. 18-43, 2017.

[29] M. Ghobakhloo and T. S. Hong, "IT investments and business performance improvement: the mediating role of lean manufacturing implementation,” Int. J. Prod. Res., no. June, pp. 1-18, Apr. 2014. 